\title{
THERMAL DEPOSITION ANALYSIS DURING DISRUPTIONS ON DIII-D USING INFRARED SCANNERS
}

\author{
by \\ R.L. LEE, C.J. LASNIER, A.W. HYATT, \\ A.G. KELLMAN, and P.L. TAYLOR
}




\title{
THERMAL DEPOSITION ANALYSIS DURING DISRUPTIONS ON DIII-D USING INFRARED SCANNERS
}

\author{
by \\ R.L. LEE, C.J. LASNIER,* A.W. HYATT, \\ A.G. KELLMAN, and P.L. TAYLOR
}

This is a preprint of a paper presented at the 16th IEEE/NPSS Symposium on Fusion Engineering, September 30-October 5, 1995, Champaign, Illinois, and to be printed in the Proceedings.

Work supported by

U.S. Department of Energy Contracts

DE-AC03-89ER51114 and W-7405-ENG-48

*Lawrence Livermore National Laboratory

GENERAL ATOMICS PROJECT 3466

DECEMBER 1995 


\section{DISCLAMMER}

Portions of this document may be illegible in electronic image products. Images are produced from the best available original document. 


\title{
Thermal Deposition Analysis During Disruptions on DIII-D Using Infrared Scanners*
}

\author{
R.L. Lee, ${ }^{\text {a C.J. Lasnier, }}{ }^{\mathrm{b}}$ A.W. Hyatt, ${ }^{\mathrm{a}}$ A.G. Kellman, ${ }^{\text {a P.L. Taylor }}{ }^{\mathrm{a}}$ \\ ${ }^{a} G e n e r a l$ Atomics, P.O. Box 85608, San Diego, California 92186-9784 \\ ${ }^{b}$ Lawrence Livermore National Laboratory, P.O. Box 808, Livermore, California 94551-9900
}

\begin{abstract}
The DIII-D tokamak generates plasma discharges with currents up to $3 \mathrm{MA}$ and auxiliary input power up to $20 \mathrm{MW}$ from neutral beams and $4 \mathrm{MW}$ from radio frequency systems. In a disruption, a rapid loss of the plasma current and internal thermal energy occurs and the energy is deposited onto the torus graphite wall. Quantifying the spatial and temporal characteristics of the heat deposition is important for engineering and physics-related issues, particularly for designing future machines such as ITER. Using infrared scanners with a time resolution of $120 \mu \mathrm{s}$, measurements of the heat deposition onto the all-graphite walls of DII-D during two types of disruptions have been made. Each scanner contains a single point detector sensitive to $8-12 \mu \mathrm{m}$ radiation, allowing surface temperatures from $20^{\circ} \mathrm{C}$ to $2000^{\circ} \mathrm{C}$ to be measured. A zinc selenide window that transmits in the infrared is used as the vacuum window. Views of the upper and lower divertor regions and the centerpost provide good coverage of the first wall for single and double null divertor discharges. During disruptions, the thermal energy is not deposited evenly onto the inner surface of the tokamak, but is deposited primarily in the divertor region when operating diverted discharges. Analysis of the heat deposition during a radiative collapse disruption of a 1.5 MA discharge revealed power densities of $300-350 \mathrm{MW} / \mathrm{m}^{2}$ in the divertor region. During the thermal quench of the disruption, the energy deposited onto the divertor region was more than $70 \%$ of the stored thermal energy in the discharge prior to the disruption. The spatial distribution and temporal behavior of power deposition during high $\beta$ disruptions will also be presented.
\end{abstract}

\section{INTRODUCTION}

The DIII-D tokamak, operated by General Atomics, is used for studies in magnetic confinement of high temperature deuterium plasma discharges. The versatility of DIII-D allows plasma discharges with various shapes, including ITERlike discharges, to be performed. Auxiliary heating from neutral beams and rf systems provides up to $24 \mathrm{MW}$ of input power and this translates into more than $3 \mathrm{MJ}$ of stored energy in the plasma. A disruption of the plasma, the sudden decrease in the thermal energy or current of the discharge, results in deposition of the energy onto the surrounding walls of the tokamak. During a disruption, the energy deposited onto plasma facing components can cause damage and it is important to characterize this heat flux to properly design and evaluate the erosion and lifetime of these components. This paper will concentrate on infrared scanner analysis of the spatial and temporal characteristics of heat deposition onto the divertor floor in DIII-D during disruptions.

\section{EXPERIMENTAL SETUP}

Inframetrics 525 IR scanners, coupled with Panasonic video tape recorders, are central to the data gathering system. The 525 scanners contain a single point $\mathrm{HgCdTe}$ detector sensitive in the range of $8-12 \mu \mathrm{m}$ and a $2-\mathrm{D}$ image view is obtained by using two orthogonal scanning mirrors to direct the image to the detector. The TV image thus produced is a standard interlaced image having two $16.7 \mathrm{~ms}$ fields per frame. For the purpose of capturing events having a time scale of a few milliseconds, one mirror is held stationary while the other mirror scans a single spatial slice of the image with an $8 \mathrm{kHz}$ frequency. The resultant TV image is again composed of two $16.7 \mathrm{~ms}$ fields per frame, but each field contains time dependent data for the particular spatial slice of the image. Of each $16.7 \mathrm{~ms}$ field, usable data is contained in a $12 \mathrm{~ms}$ portion of the image. The remaining nearly $5 \mathrm{~ms}$ is used for the TV vertical retrace and placement of a scanner-generated grayscale and shot related data such as number and time.

Fig. 1 shows the general setup used to obtain heat flux data of the lower divertor region in DIII-D. The details of the optical setup and a brief description of the temperature inversion method used to calculate heat flux have been discussed elsewhere and will not be presented here [1].

Two toroidally separate views of the floor, or divertor region, of DIII-D were used to obtain heat deposition profiles during disruptions. The toroidal locations were $60^{\circ}$ and $165^{\circ}$ and the systems were set up to view narrow radial slices of the floor. Due to the independent internal clocks driving each scanner, temporal overlapping of specific shot data could not be guaranteed.

\section{FORCED DISRUPTION EXPERIMENTS}

Characterization experiments were performed in which disruptions were forced to occur by either radiative collapse due to argon impurity injection or by reaching the $\beta$ limit due to injection of high power neutral beams [2].

\footnotetext{
*Work supported by the U.S. Department of Energy under Contract Nos. DE-AC03-89ER51114 and W-7405-ENG-48.
} 


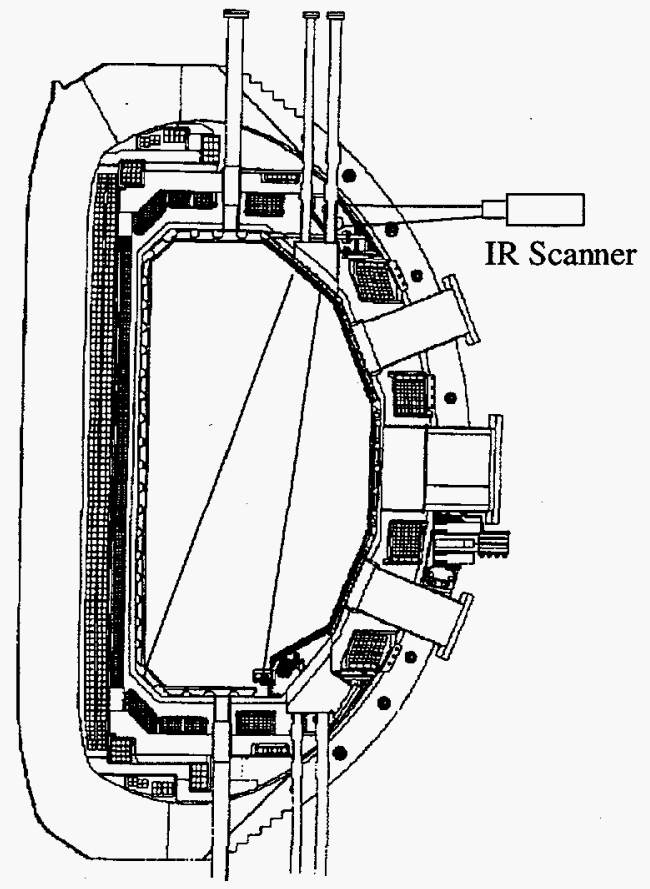

Fig 1. Cross sectional view of DIII-D showing general location of IR scanner and divertor target region.

\section{IMPURITY INJECTION DISRUPTIONS}

Fig. 2 shows the plasma current, central SXR, the total radiated power as measured from a 48 channel bolometer, the stored energy, the radial position of the plasma geometric center, and the power density, $P_{\text {div }}$, incident onto a $1 \mathrm{~cm}$ wide radial slice of the divertor for a discharge (shot 81167) which disrupted after argon was introduced to the plasma. The thermal quench occurs rapidly, as evidenced in the sudden drop of the central soft $x$-ray amplitude beginning at $2.035 \mathrm{~s}$. Central re-heating of the plasma begins at $2.039 \mathrm{~s}$ and the final thermal quench is complete by $2.045 \mathrm{~s}$. The stored energy of the plasma also decreases from a maximum of about $1.1 \mathrm{MJ}$ to $0.16 \mathrm{MJ}$ by the end of the first phase of the thermal quench. The stored energy continues to decrease until the final thermal quench is complete. The total radiated power begins to increase sharply at the onset of the thermal quench, reaches a maximum of about $120 \mathrm{MW}$ just after the thermal quench and decreases during the current quench. The time average used for the radiated power signal is averaged over $8 \mathrm{~ms}$. The heat flux onto the divertor, $P_{\text {div }}\left(\mathrm{MW} / \mathrm{m}^{2}\right)$, rises sharply during the first phase of the thermal quench. The heat flux threshold of the overall system at this toroidal location for the scanner settings used is about $10 \mathrm{MW} / \mathrm{m}^{2}$ and no heat flux above this threshold is observed prior to the thermal quench. Data from $2.041 \mathrm{~s}$ to $2.046 \mathrm{~s}$ was not obtained.

Fig. 3 shows the heat flux to the divertor as a function of time and radial position during the first phase of the thermal quench. Continuous heat flux near the outer strike point $(\mathrm{R}=$ $1.51 \mathrm{~m}$ ) is observed and reaches a peak at $2.038 \mathrm{~s}$. Divertor heat flux profiles for three time slices during the thermal

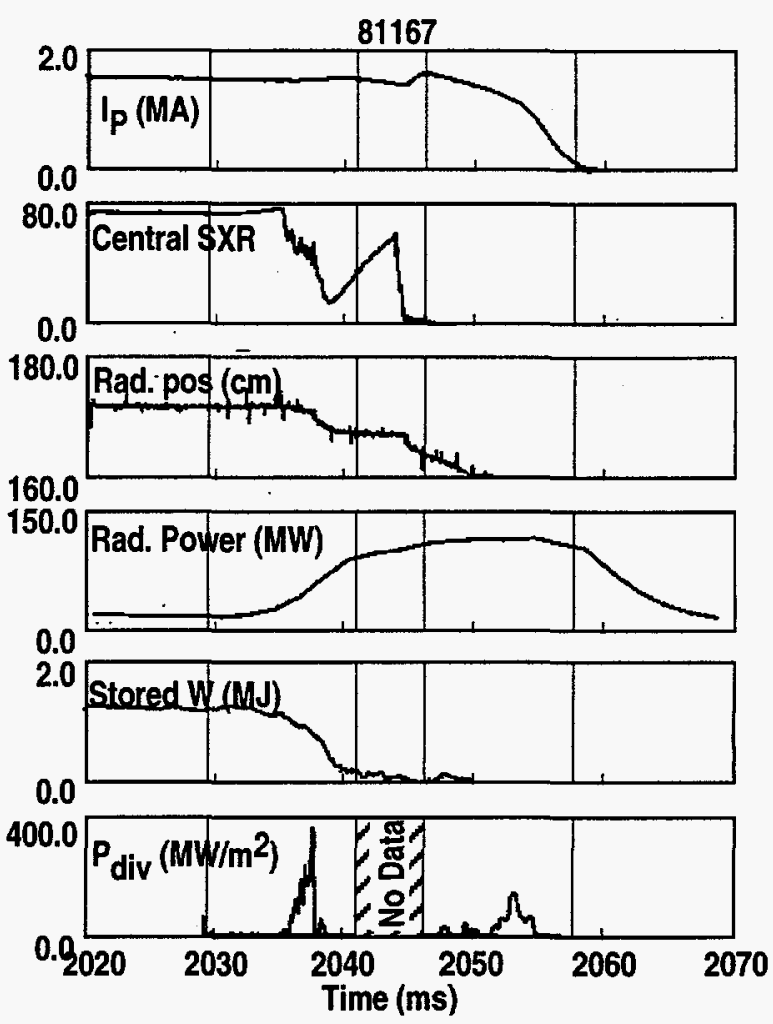

Fig. 2. Plasma current, SXR, radial position, radiated power, stored energy, and heat flux to the divertor for a discharge that disrupted due to argon injection. The radiated power data is averaged over an $8 \mathrm{~ms}$ period. Vertical lines indicate when IR scanner data was obtained. No IR data was obtained from $t=2.041 \mathrm{~s}$ to $2.0463 \mathrm{~s}$.

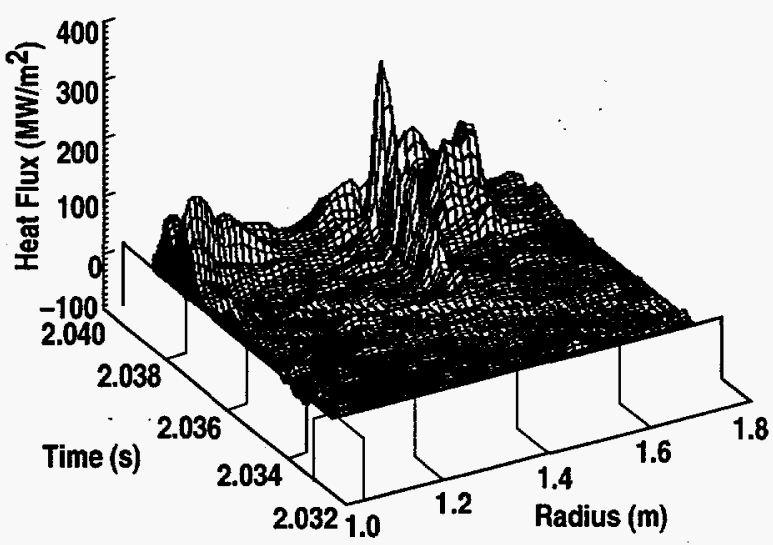

Fig. 3. Heat flux to the divertor in DIII-D for a discharge that disrupted due to argon injection. The inner strike point location is $R \approx 1.09 \mathrm{~m}$, and the outer strike point location is $\mathrm{R} \approx 1.51 \mathrm{~m}$.

quench are shown in Fig. 4 with the corresponding radial positions of the inner and outer strike points as calculated using magnetic diagnostics data and the MHD equilibrium code EFIT. The heat flux at the start of the thermal quench has risen above the sensitivity of the scanner and the peak heat flux observed increases from $30 \mathrm{MW} / \mathrm{m}^{2}$ to $350 \mathrm{MW} / \mathrm{m}^{2}$ at $R \approx 1.43 \mathrm{~m}$. The main heat flux during the initial thermal quench is in a region about $7-9 \mathrm{~cm}$ radially inboard of the 


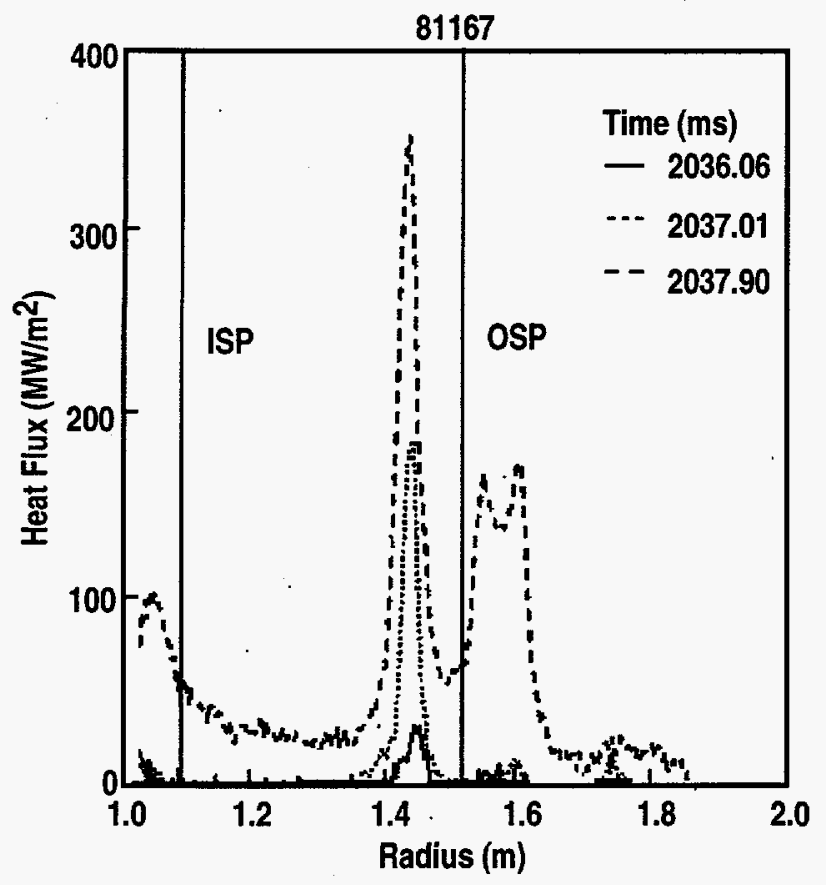

Fig. 4. Divertor heat flux during an argon impurity disruption for $t=$ $2.036 \mathrm{~s}$ (solid), $2.037 \mathrm{~s}$ (dotted), and $2.0379 \mathrm{~s}$ (dashed). The inner strike point (ISP) is at $\mathrm{R}=1.09 \pm 0.01 \mathrm{~m}$, and the outer strike point (OSP) is at $1.51 \pm 0.01 \mathrm{~m}$.

outer strike point. The width of the main spike varies little during the evolution of the disruption, having an average full width at half maximum (FWHM) of $2.8 \mathrm{~cm}$. By $2.0379 \mathrm{~s}$, the heat flux inboard of the inner strike point and outboard of the outer strike point rises rapidly to $100-150 \mathrm{MW} / \mathrm{m}^{2}$ and each has a FWHM two to three times as broad as that of the main heat spike. Each of the strike points remain relatively stationary throughout the thermal quench. No IR data was obtained during the thermal quench following the plasma re-heating.

Heat deposition during the current quench was observed at $\mathrm{R}=1.05 \mathrm{~m}$, near the inner strike point $(\mathrm{R}=1.09 \mathrm{~m})$. The maximum power density was about $150 \mathrm{MW} / \mathrm{m}^{2}$. The heat deposition observed near the outer strike point during the current quench was not peaked, but spread across the region for $\mathrm{R}>1.4 \mathrm{~m}$.

\section{HIGH BETA DISRUPTIONS}

Experiments were also carried out in which injected neutral beam power was increased until the $\beta$ limit was reached and the discharge disrupted. Fig. 5 shows the discharge evolution for a 1.5 MA single null divertor discharge (shot 84359), with injected neutral beam power of $18 \mathrm{MW}$ and an edge safety factor of $q_{95}=2.4$. The central SXR signal and stored energy decrease starting around $2.195 \mathrm{~s}$ with the growth of a locked mode and a more rapid loss of thermal energy begins at $\approx 2.202 \mathrm{~s}$. The radiated power increases to approximately $70 \mathrm{MW}$ during the thermal quench. The peak value of normalized $\beta\left(\beta_{\mathrm{N}}=\beta /\right.$ Iab $)$ achieved in this discharge was 3.0 and was 2.8 prior to the thermal quench. The stored energy at the start of the thermal quench was $0.9 \mathrm{MJ}$. The thermal quench is complete by $2.212 \mathrm{~s}$.

Fig. 6 shows the power to the divertor during this interval is concentrated radially inward of the inner strike region and radial movement of the flux peak position was observed. The hatched area denotes excursions in the strike point location along the radius. Early in the disruption (2.204 s) the heat flux peak is at $R=1.225 \mathrm{~m}$ (solid line). Within $2 \mathrm{~ms}$, the peak has broadened and moved inward about $5 \mathrm{~cm}$ (dotted line). The maximum heat flux of about $160 \mathrm{MW} / \mathrm{m}^{2}$ occurs at $\mathrm{R}=1.20 \mathrm{~m}$ (dashed line). At the end of the thermal quench $(2.210 \mathrm{~s})$, the peak heat flux near the inner strike region has been reduced to about $50 \mathrm{MW} / \mathrm{m}^{2}$. Very little power is observed near the outer strike point.

Heat flux measurements during the current quench show a widely dispersed spatial pattern, extending from $R=1.05 \mathrm{~m}$ to $R=1.45 \mathrm{~m}$ with a peak of less than $60 \mathrm{MW} / \mathrm{m}^{2}$.

\section{DISCUSSION}

Heat flux to the divertor regions during disruptions of single null discharges has been observed to occur near to, but not necessarily coincident with, the strike points. In the injected

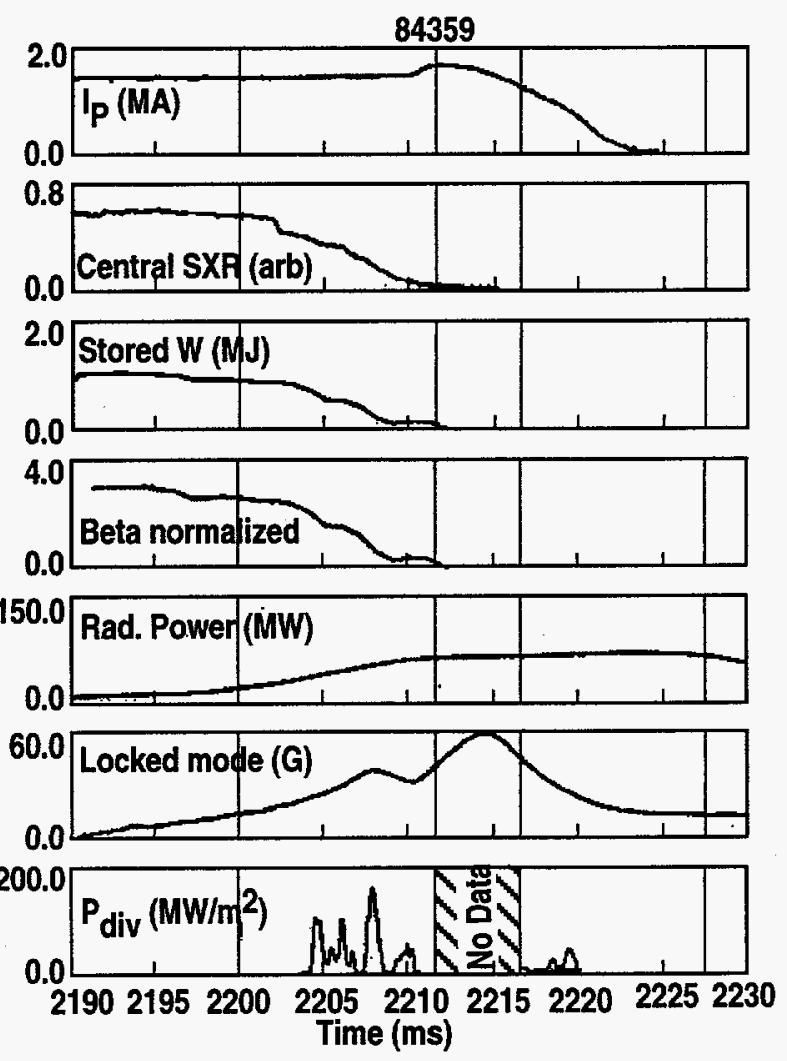

Fig. 5. Plasma current, SXR, stored energy, normalized $\beta$, radiated power, radial magnetic perturbation, and heat flux to the divertor for a discharge that disrupted after reaching the $\beta$ limit. Vertical lines indicate when IR scanner data was obtained. No IR data was obtained from $\mathrm{t}=2.2115 \mathrm{~s}$ to $2.2165 \mathrm{~s}$. 


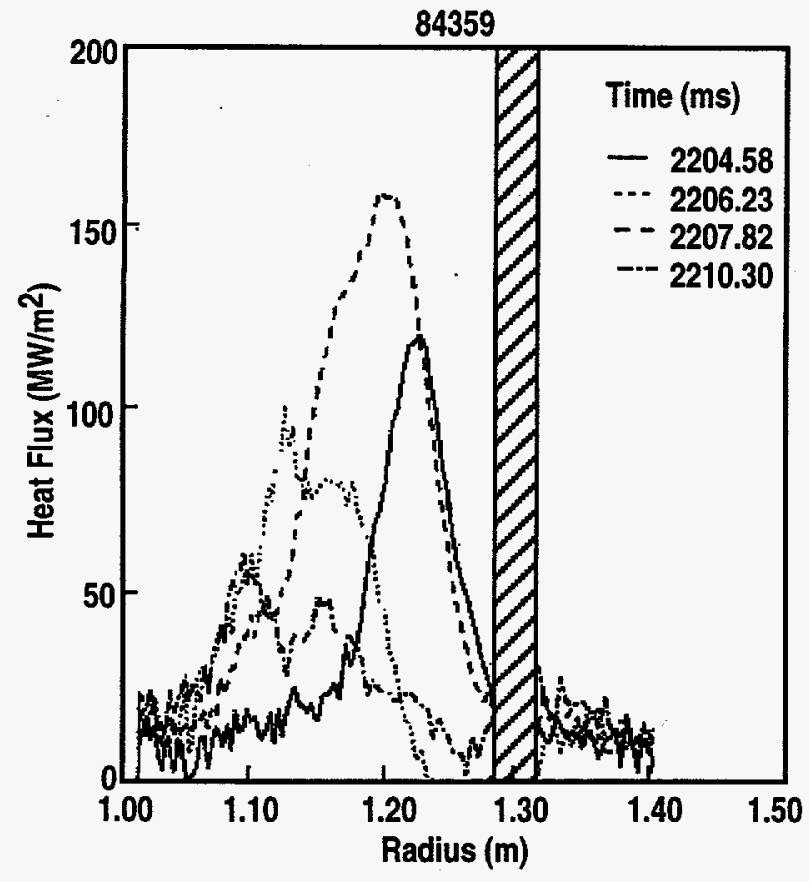

Fig. 6. Radial movement of the primary divertor heat flux during a $\beta$ limit disruption. The hatched area represents the divertor region over which the inner strike point moved during the disruption.

impurity disruption case, most of the power was deposited near the outer strike point with the maximum heat flux of about $350 \mathrm{MW} / \mathrm{m}^{2}$ in the private flux region $7-9 \mathrm{~cm}$ inside the outer strike point. In the high $\beta$ case, the major heat flux was radially inward of the inner strike region. The continuous heat flux observed during the radiative collapse disruption is in contrast to the pulsed heat deposition of the disruption at high $\beta$. While these attributes may not be specific to the type of disruption, they indicate heat flux to the divertor region during disruptions is not a simple phenomenon.

Table I is a comparison of energy input and energy loss for the impurity induced disruption and high $\beta$ disruption cases. The input energy represents the change in the plasma stored energy and includes the ohmic and neutral beam power input during the thermal quench. From the measured energy deposited along a radial chord of the divertor and assuming toroidal symmetry, the energy deposited onto the divertor can be calculated. About $70 \%$ of the input energy in the first phase of the thermal quench for the impurity injection disruption (shot 81167) can be accounted for in the divertor heat flux. Over $90 \%$ of the energy input during the thermal quench of the high $\beta$ disruption can be found in the divertor heat flux.

A significant portion of the overall input energy is lost through radiation, but determining how to partition the radiated energy between the thermal quench and current quench is difficult because the $8 \mathrm{~ms}$ integration time of the bolometer is comparable to the duration of the disruption. However, it can be seen from Figs. 2 and 5 that the radiated power is very high during the disruptions. Preliminary analysis indicates that during the current quench, the dominant energy loss mechanism is radiation.

Table I

Energy input and loss mechanisms during impurity injection disruption and high $\beta$ disruption

\begin{tabular}{|c|c|c|}
\hline Shot & 81167 & 84359 \\
\hline $\begin{array}{l}\text { Disruption mechanism } \\
\text { Disruption phase }\end{array}$ & $\begin{array}{l}\text { Ar inject. } \\
1 \text { st phase, } \\
\text { thermal } \\
\text { quench }\end{array}$ & $\begin{array}{l}\text { High } \beta \\
\text { Thermal } \\
\text { quench }\end{array}$ \\
\hline $\begin{array}{l}\text { Input Energy Mechanism } \\
\Delta \text { Stored Energy } \\
\text { Ohmic input } \\
\text { NBI input }\end{array}$ & $\begin{array}{l}944 \mathrm{~kJ} \\
<10 \\
46\end{array}$ & $\begin{array}{l}842 \mathrm{~kJ} \\
<50 \\
165\end{array}$ \\
\hline Total stored energy & $1000 \mathrm{~kJ}$ & $1057 \mathrm{~kJ}$ \\
\hline $\begin{array}{l}\text { Energy Loss Mechanism } \\
\text { Measured divertor heat flux: } \\
\text { Energy during thermal quench } \\
\text { Energy during current quench }\end{array}$ & $\begin{array}{l}700 \mathrm{~kJ} \\
370 \mathrm{~kJ}\end{array}$ & $\begin{array}{l}988 \mathrm{~kJ} \\
750 \mathrm{~kJ}\end{array}$ \\
\hline $\begin{array}{l}\text { Total measured energy deposited onto } \\
\text { divertor during disruption }\end{array}$ & $1370 \mathrm{~kJ}$ & $1738 \mathrm{~kJ}$ \\
\hline Total radiated energy during disruption & $2670 \mathrm{~kJ}$ & $1200 \mathrm{~kJ}$ \\
\hline
\end{tabular}

\section{FUTURE WORK}

System enhancements include synchronization of IR scanners at different locations on DIII-D. Due to the independent scanning nature of different IR systems, a two-fold problem exists in capturing data. First, because of the scanning nature of TV imaging electronics, data from fast events can be completely missed or only partially recorded during operations. The vertical video scan performed for each $16.7 \mathrm{~ms}$ field, coupled with needed alphanumeric and grayscale data generated within the electronics and displayed on the image, results in a $5 \mathrm{~ms}$ interval in which no useful data is obtained. This problem can be reduced by resizing or removing the displayed information during actual data gathering. Second, although there are two scanners at different toroidal locations, it is difficult to obtain data on toroidal asymmetries because the scanning mirrors in each system are not synchronous with each other. We are investigating synchronizing electronics to alleviate this problem.

\section{REFERENCES}

[1] D.N. Hill, R. Ellis, S.W. Fergusen, D.E. Perkins, Rev. Sci. Instrum. 59, p. 1878, 1988.

[2] P.L. Taylor, et al., Tripartite Workshop on Termination of High Performance Regimes and Disruptions, JET Joint Undertaking, Abingdon, England, July 10-12, 1995. 


\section{DISCLAIMER}

This report was prepared as an account of work sponsored by an agency of the United States Government. Neither the United States Government nor any agency thereof, nor any of their employees, make any warranty, express or implied, or assumes any legal liability or responsibility for the accuracy, completeness, or usefulness of any information, apparatus, product, or process disclosed, or represents that its use would not infringe privately owned rights. Reference herein to any specific commercial product, process, or service by trade name, trademark, manufacturer, or otherwise does not necessarily constitute or imply its endorsement, recommendation, or favoring by the United States Government or any agency thereof. The views and opinions of authors expressed herein do not necessarily state or reflect those of the United States Government or any agency thereof. 